\title{
POTENCIAL TRANSFORMADOR DO ENSINO SUPERIOR EM CABO VERDE
}

Luís Rodrigues $^{(*)}$

Embora tenha uma história ainda breve, o Ensino Superior (ES) em Cabo Verde tem mostrado uma forte dinâmica ao longo das últimas décadas, mudando a forma como os jovens deste país arquitetam os seus projetos pessoais e profissionais. Ainda assim, falta analisar se este sistema de ensino contribui para a efetiva transformação que poderá trazer à sociedade cabo-verdiana. Neste artigo,o nosso objetivo é examinar o potencial transformador que o Ensino Superior poderá ter na sociedade cabo-verdiana.

Para tal, tomaremos como referencial a palestra proferida por Castells (2009), na qual reflete sobre o Ensino Superior, não nas suas inúmeras instituições, mas como um sistema complexo e que combina diferentes funções. Estes papéis históricos não ocorreram sempre ao mesmo tempo e têm assumido diferentes feições (CLOETE; MAASEN; BAILEY, 2015), mas são essenciais no traçar das relações do sistema de Ensino Superior com a sociedade, independentemente do contexto histórico, geográfico e social em que inserem (CASTELLS, 2009).

De forma a poder responder ao nosso objetivo fundamental, traçaremos um quadro geral do sistema de Ensino Superior em Cabo Verde, complementado com uma resenha histórica do mesmo, que dividiremos em três partes distintas, tentando compreender o percurso das diferentes Instituições de Ensino Superior (IES) do país.

Na sequência, apresentaremos alguns dos dados mais recentes sobre o Ensino Superior em Cabo Verde, obtidos no Anuário Estatístico do Ensino Superior (CABO VERDE, 2017), que fornecem dados novos em relação à bibliografia já existente (BANCO MUNDIAL, 2012; BRITO, 2017; TAVARES, 2010). Nesta análise, o foco estará na acessibilidade e equidade do Ensino Superior em Cabo Verde e na sua qualidade. O primeiro aspeto prende-se aos estudantes do país. Em que áreas estudam? Qual a sua origem geográfica e social e até que ponto representam a diversidade do país? A qualidade será debatida como fator fundamental da própria legitimação deste subsistema (VARELA; PACHECO, 2014), a despeito da falta de políticas concretas neste sentido (BANCO MUNDIAL, 2012; VARELA; PACHECO, 2014).

\footnotetext{
${ }^{(*)}$ Mestre em Português como Língua Estrangeira/Língua Segunda, Professor e Chefe do Departamento de Ciências da Educação, Filosofia e Letras da Universidade de Santiago, em Cabo Verde.E-mail: luisrodrigues.22@gmail.com.
} 
Assumimos, neste artigo, o conceito de relevância do Ensino Superior como a sua capacidade de transformar as sociedades com as quais interage (CLOETE; MAASEN; BAILEY, 2015; MHLANGA, 2008). Desta forma, cruzaremos dados relativos à sociedade cabo-verdiana e os sinais dados pelas diferentes IES do país em termos econômicos, sociais e culturais. A pretensão é problematizar a relevância do Ensino Superior em Cabo Verde.

Por fim, retomando os papéis históricos do Ensino Superior propostos por Castells (2009), terminaremos esta reflexão olhando para a real concretização destas funções, por um lado, e o potencial transformador que este jovem subsistema de ensino tem na sociedade cabo-verdiana.

\section{FUNÇÕES DO ENSINO SUPERIOR}

De forma sucinta, Castells (2009) apresenta quatro grandes funções, ao longo da história, que as Universidades ${ }^{2}$ têm tido. Em primeiro lugar, a produção de valores e legitimação social. A sua própria existência como lugar, por excelência, de produção e divulgação de conhecimento especializado que a levou, simultaneamente, à seleção das elites dominantes. Também, desde o seu início, embora de forma mais vincada apenas alguns séculos mais tarde (CLOETE; MAASEN; BAILEY, 2015), as IES também são responsáveis pela formação da força de trabalho. Por fim, e com grande predominância em tempos bem recentes, as universidades têm sido responsáveis pela produção de conhecimento científico.

A primeira função apresentada, produção de valores e legitimação social, significa a assunção das Instituições de Ensino Superior como aparelhos ideológicos. Muitas destas instituições nasceram como estabelecimentos de cunho religioso; outras advogaram, no passado, a superioridade das metrópoles colonizadoras; muitas defendem valores cívicos (CLOETE; MAASEN; BAILEY, 2015). A verdade é que o Ensino Superior incorpora valores existentes ao seu redor, divulgando-os, embora tenha também a capacidade de os alterar, numa relação dialógica com a sociedade (DAHMS; LYBECK, 2014).

O segundo papel, seleção das elites dominantes, é um dos mais importantes (CLOETE; MAASEN; BAILEY, 2015). O acesso ao Ensino Superior é, tradicionalmente, privilégio das classes dominantes, que, pela frequência universitária e a legitimação que ela confere, reforçam essa posição social. Mesmo com a maior democratização no acesso, nas últimas décadas (CLOETE, MAASEN; BAILEY, 2015; LIMA, 2014), há desigualdade na capacidade de selecionar elites por

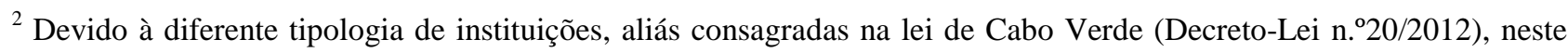
artigo utilizaremos a expressão Instituições de Ensino Superior.
} 
parte de determinadas instituições em detrimento de outras, num processo em que hierarquias sociais são reproduzidas no contexto acadêmico (CASTELLS, 2009; CLOETE; MAASEN; BAILEY, 2015).

Embora muitas vezes visto como o seu papel fundamental, a formação da força laboral é apenas uma das funções do Ensino Superior (CASTELLS, 2009). O conhecimento altamente especializado é, frequentemente, transponível para funções de prestígio no mercado de trabalho. Contudo, conflitos mais recentes têm revelado alguma incapacidade das IES em conciliar os interesses dos governos e as necessidades das economias com a sua própria natureza. Daí resulta um descompasso entre as formações oferecidas e as reais necessidades laborais (LIMA, 2014).

A última grande função, generalizada apenas no século XX (CASTELLS, 2009), é a produção de conhecimento científico. Neste sentido, as IES são centros de inovação e desenvolvimento técnico e científico. Contudo, nem todas conseguem desempenhar este papel de forma cabal. A pesquisa sistemática e a sua divulgação exigem políticas concertadas entre diferentes atores, sejam eles governamentais, acadêmicos ou empresariais, o que nem sempre acontece (CLOETE; MAASEN; BAILEY, 2015).

Estes papéis históricos persistem ainda hoje e continuarão enquanto as Universidades mantiverem a sua natureza como tal. Na prática, o sistema de Ensino Superior incorpora-os em simultâneo, mas cada instituição pode decidir especializar-se, mediante as suas valências e projeto (CASTELLS, 2009). Desta forma, as Instituições de Ensino Superior têm assumido novas formulações decorrentes de processos de internacionalização (BLESSINGER; ANCHAN, 2015) e como forma de dar resposta aos desafios hodiernos (CASTELLS, 2009; LIMA, 2014).

\section{O ENSINO SUPERIOR EM CABO VERDE}

\section{Tipos de Instituições e Graus Acadêmicos}

De acordo com o Decreto-Lei 20/2012 (Regime Jurídico das Instituições de Ensino Superior) e o Decreto-Lei 22/2012 (Regime Jurídico dos Graus e Diplomas do Ensino Superior), em Cabo Verde, o sistema de Ensino Superior compreende instituições públicas e privadas ${ }^{3}$. Estas, ao mesmo tempo, dividem-se em Universidades e Institutos de Ensino Politécnico ${ }^{4}$.

Ao abrigo da lei, todas estas instituições podem realizar ciclos de estudos conferentes de quatro graus acadêmicos, sintetizados na Tabela 1:

\footnotetext{
${ }^{3}$ Decreto-Lei 20/2012, Art. $3^{\circ}$.

${ }^{4}$ Decreto-Lei 20/2012, Art. $6^{\circ}$.
} 
Tabela 1. Elaboração própria com base no Decreto-Lei 22/2010

\begin{tabular}{|c|c|}
\hline Grau Académico & Caraterísticas \\
\hline CESP - Cursos de Ensino & - 3 a 4 semestres \\
\hline Superior Profissionalizante & - Parte da formação em contexto de trabalho \\
\hline Licenciatura & - 6 a 8 semestres \\
\hline \multirow[t]{2}{*}{ Mestrado } & - 3 a 4 semestres \\
\hline & - Dissertação ou Estágio \\
\hline \multirow[t]{2}{*}{ Doutoramento } & - Curso opcional \\
\hline & - Tese \\
\hline
\end{tabular}

A ideia é de progressão vertical. Os alunos podem matricular-se num CESP ou Licenciatura após completarem 12 anos de escolaridade. O Mestrado implica ter completado uma Licenciatura e o Doutoramento prevê que o aluno seja já Mestre. Naturalmente, o grau de especialização aumenta a cada nível. Terminando um CESP, o aluno pode obter equivalências em Licenciaturas em áreas afins, sendo obrigado, apenas, a cumprir as restantes unidades curriculares de forma a terminar a Licenciatura. $^{5}$

\section{BREVE HISTÓRICO DAS IES EM CABO VERDE}

Após a independência, em 1975, não havia, em Cabo Verde, qualquer sistema ou instituição de Ensino Superior. Contudo, as cada vez maiores demandas em termos de necessidade de mercado de trabalho e de maior especialização dos recursos humanos (LANGA, 2013; BANCO MUNDIAL, 2012) levaram ao nascimento e posterior expansão deste subsistema de Ensino. Neste artigo, de forma sucinta, tentaremos explicar este processo em três períodos distintos: uma fase de nascimento, até ao final da década de 90 do século XX; uma segunda fase de expansão, na primeira década do século XX, e uma última fase de consolidação, desde o início da segunda década deste século.

Como frequentemente acontece nas sociedades pós-coloniais, a primeira área em que a imperiosa necessidade de formação de profissionais qualificados se faz sentir é a educação (CLOETE; MAASEN; BAILEY, 2015). Assim, logo em 1979, nasceu a Escola de Formação de Professores, pela Lei 70/79, com uma forte vertente, também, de ensino à distância (LANGA,

\footnotetext{
${ }^{5}$ De acordo com o Decreto-Lei 22/2012.
} 
2013). Aqui, o objetivo era formar professores, novos e em exercício (Idem). Contudo, estamos ainda longe de um sistema, de fato, de Ensino Superior (LANGA, 2013; SCHWARTZMANN, 2011).

Esse sistema, em Cabo Verde, apenas começa a dar os seus primeiros passos durante a década de 90. Com efeito, ao longo desta década, nasceram, no país, vários institutos vocacionados para o Ensino Pós-Secundário ou Profissionalizante (LANGA, 2013), em áreas como a Educação, as Ciências Agrónomas ou as Ciências do Mar. Por detrás da sua abertura estava a necessidade de, após a abertura política, dotar o país de profissionais capazes de melhor responder às necessidades da economia. (BANCO MUNDIAL, 2012; LANGA, 2013; TAVARES, 2010). Até então, toda e qualquer formação superior tinha de ser feita no estrangeiro, tornando, para muitos jovens, esse um sonho impossível (BRITO, 2017; LANGA, 2013). Na Tabela 2, elencamos as várias instituições nascidas durante este período.

Tabela 2. IES criadas durante a década de noventa do século XX (BANCO MUNDIAL, 2012; LANGA, 2013)

\begin{tabular}{lc}
\hline Ano & Instituição \\
\hline 1992 & INIDA - Instituto Nacional de Desenvolvimento Agrário \\
1994 & IP - Instituto Pedagógico (em 2014 é renomeado para IUE - Instituto \\
1996 & Universitário de Educação) \\
1996 & ISECMAR - Instituto Superior de Engenharia e Ciências do Mar \\
1998 & INAG - Instituto Superior de Educação \\
\hline
\end{tabular}

Todos estes institutos eram de natureza pública e geograficamente localizados em áreas associadas às suas áreas de intervenção, numa clara tentativa de resposta a necessidades laborais e económicas. Estas instituições, ainda assim, dão corpo à fase que denominamos de nascimento do Ensino Superior em Cabo Verde.

Ainda assim, estávamos aquém da efetiva existência de um Ensino Superior como tal. Vários pequenos institutos, deslocalizados e sem uma verdadeira natureza de Academia,não supriam as reais necessidades do país, nem davam resposta às ambições dos governos à época (TAVARES, 2010; TOLENTINO, 2006). 
Por isso mesmo, em 2000, é publicado o Decreto-Lei 33/2000, que previa a abertura de uma Universidade Pública no país (BANCO MUNDIAL, 212; LANGA, 2013). Mas, curiosamente, a primeira universidade a abrir as suas portas foi a Universidade Jean Piaget, privada, nascida de um Instituto, com o mesmo nome, com sede em Portugal. A Universidade de Cabo Verde, a primeira universidade pública do arquipélago nasceu apenas em 2006. Esta nasce aglomerando a maioria dos Institutos anteriormente existentes e, ao longo do tempo, acabou por os absorver todos (LANGA, 2013; TOLENTINO, 2006). O último, já mais recentemente, foi o IUE - Instituto Universitário da Educação, em 2017.

A primeira década do século XX foi, efetivamente, um período de grande fulgor no Ensino Superior nacional, tendo sido criadas todas as nove Instituições de Ensino Superior existentes ainda hoje em Cabo Verde. Oito delas são privadas, entre Institutos Superiores e Universidades. Na Tabela 3, a sua listagem.

Tabela 3. IES criadas durante a década de noventa do século XX (BANCO MUNDIAL, 2012; LANGA, 2013)

\begin{tabular}{ll}
\hline Ano & \multicolumn{1}{c}{ Instituição } \\
\hline 2001 & Universidade Jean Piaget \\
\hline 2002 & IESIG - Instituto de Estudos Superiores Isidoro da Graça (em 2010 renomeada \\
\hline 2006 & Universidade de Cabo Verde \\
\hline 2006 & ISCJS - Instituto Superior de Ciências Jurídicas e Sociais \\
\hline 2007 & Universidade Lusófona Baltasar Lopes da Silva \\
\hline 2007 & UNICA - Eniversidade Intercontinental de Cabo Verde \\
\hline 2008 & ISCEE - Instituto Superior de Ciências Económicas e Empresariais \\
\hline 2008 & US - Universidade de Santiago \\
\hline
\end{tabular}

Num período de apenas sete anos, nascem nove Instituições de Ensino Superior, correspondendo ao período que denominamos de expansão do Ensino Superior. Naturalmente, esta explosão verificou-se, também, ao nível do número de alunos: em 2009/10 já eram 10144 discentes 
matriculados no Ensino Superior, tendo passado de uma Taxa de Escolarização Bruta de 2\% em 2000, para 15\%, em 2009 (LANGA, 2013).

Neste ponto, Cabo Verde acompanhou a tendência geral do continente africano, de aumento do número de alunos e maior aposta nas políticas públicas neste setor (CLOETE; MAASEN; BAILEY, 2015). As forças da globalização, por fatores políticos, econômicos, socioculturais e tecnológicos, são catalisadores de mudanças ao nível da democratização das sociedades, tornando mais prementes as apostas na inovação e no ensino. Consequentemente, as instituições educativas, e as de Ensino Superior são aquelas que, pela sua natureza, mais respondem as estas demandas, são alvo de maior procura, levando a maior diversidade na população estudantil e de número e tipo de Instituições de Ensino Superior. Simultaneamente, aumenta a pressão, para que estas respondam às necessidades da sociedade e da economia (BLESSINGER; ANCHAN, 2015).

Uma das particularidades de Cabo Verde, contudo, prende-se ao forte peso relativo do ensino privado neste setor. Das nove instituições nascidas na primeira década do século XXI, oito são privadas. Atualmente, estas instituições têm, inclusive, um número superior de matriculados em relação à pública (CABO VERDE, 2017). Acreditamos, tal como Schwartzman (2011), que houve abertura por parte das entidades públicas nacionais na "partilha” das responsabilidades e custos inerentes a um sistema de ES, acompanhado de vários projetos institucionais e, eventualmente, pessoais na criação destas instituições ${ }^{6}$.

Outro aspecto importante neste boom do Ensino Superior em Cabo Verde, prende-se ao fato de só após o nascimento e funcionamento destas instituições terem sido criadas as primeiras Leis exclusivamente para a regulação deste sistema de Ensino, no ano de 2012. Embora a Lei de Bases de 1990 já contenha algumas normas em relação a este setor, a maioria das leis que regiam este subsistema de ensino eram diplomas isolados (LANGA, 2003). Este fato, acreditamos, serviu, também, como potenciador da abertura de tão elevado número de instituições e de cursos, integrado na "partilha” de responsabilidades anteriormente mencionada.

Ainda assim, este crescimento não teria condições para continuar, quer em termos econômicos, quer na própria sustentabilidade do setor (BRITO, 2017; BANCO MUNDIAL, 2012). Assim, nos últimos dez anos, não se assistiu à abertura de mais nenhuma instituição e foram criadas as principais leis que regem o setor em Cabo Verde. A despeito de muitas dúvidas em relação ao

\footnotetext{
${ }^{6}$ Será interessante aprofundar, noutros âmbitos, os projetos individuais destas instituições privadas. Embora todas elas sejam instituições nacionais, duas delas nascem de instituições portuguesas, de cariz internacional acentuado. Outras, embora projetos acadêmicos, serviram, visivelmente, como apoio legitimador a projetos políticos individuais por parte de altos responsáveis das mesmas.
} 
financiamento (BRITO, 2017) e à qualidade e relevância das instituições de ES nacionais (SCHWARTZMAN, 2011), a verdade é que a década que ora finda tem sido um período de consolidação deste setor da educação.

Com efeito, as instituições abertas na primeira década do século XXI são as que, em 2019, ainda se mantêm em funcionamento. As ofertas formativas têm aumentado e estabilizado, assim como o número de alunos, apesar de pequenas variações (CABO VERDE, 2017). Este foi o período que viu nascer as duas leis fundamentais que regem o sistema de Ensino Superior, os já aludidos Regime Jurídico das Instituições de Ensino Superior e o Regime Jurídico de Graus e Diplomas, além de outras políticas de monitorização e garantia de qualidade, como avaliações de instituições, que veremos com mais cuidado adiante neste artigo. Por fim, chamamos a atenção para a mudança de gestão do Ensino Superior operada nos finais de 2018. Até então, a tutela deste subsistema sempre estivera sob a Direção-Geral do Ensino Superior, seja em Ministérios da Educação ou de Ensino Superior, Ciência e Tecnologias. Com a criação da Agência Reguladora do Ensino Superior, em dezembro de 2018, este novo organismo vem reestruturar a relação da tutela com as instituições, na criação e manutenção de cursos e instituições, além de toda uma monitorização do sistema de Ensino Superior cabo-verdiano.

\section{OFERTAS FORMATIVAS}

Nesta fase, de acordo com os dados oficiais mais recentes, divulgados pela DGES, em 2018, embora apenas relativos ao ano letivo de 2015/2016, em Cabo Verde, os estudantes podem optar por cursos CESP, Licenciaturas, Mestrados e Doutoramentos. Estes cursos estão divididos de forma equilibrada entre as várias áreas do conhecimento, embora ainda haja mais formações disponíveis nas Ciências Sociais, Humanas, Letras e Línguas. A maioria absoluta dos cursos oferecidos são Licenciaturas, embora os anos recentes revelem um aumento da oferta de cursos de pós-graduação. Os cursos CESP, de cariz profissionalizante, apesar de serem grande aposta dos decisores públicos (BANCO MUNDIAL, 2012), ainda ficam bastante aquém, quer no número de ofertas, quer no número de alunos, conforme a Tabela 4. 
Tabela 4. Cursos por Áreas Científicas e Graus Acadêmicos (CABO VERDE, 2017)

\begin{tabular}{cccccc}
\hline Áreas & CESP & Licenciatura & Mestrado & Doutorado & TOTAL \\
\hline $\begin{array}{c}\text { Ciências Sociais, } \\
\text { Humanas, Letras e Línguas }\end{array}$ & 3 & 23 & 8 & 1 & $\mathbf{3 5}$ \\
$\begin{array}{c}\text { Ciências da Vida, } \\
\text { Ambiente e Saúde }\end{array}$ & 6 & 13 & 7 & 0 & $\mathbf{2 6}$ \\
Ciências Económicas, & 4 & 21 & 13 & 0 & $\mathbf{2 8}$ \\
Jurídicas e Políticas & & & & & $\mathbf{2 9}$ \\
Ciências Exatas, & 5 & 21 & 2 & 0 & $\mathbf{1}$ \\
Engenharia e Tecnologias & & $\mathbf{7 8}$ & $\mathbf{3 0}$ & \\
TOTAL & $\mathbf{1 8}$ & & & \\
\hline
\end{tabular}

\section{ACESSIBILIDADE E EQUIDADE NO ENSINO SUPERIOR EM CABO VERDE}

De acordo com os dados mais recentes do Ministério da Educação, frequentam o Ensino Superior em Cabo Verde cerca de 12.600 estudantes (CABO VERDE, 2017). Este valor corresponde a uma Taxa Bruta de Escolarização de 24\%. Ou seja, quase um em cada quatro jovens de Cabo Verde, em idade de frequentar o Ensino Superior, está, neste momento, matriculado numa IES. Este número, nada negligenciável, em particular em comparação com a realidade regional envolvente, pode significar um ponto de viragem interessante na realidade do país.

Neste ponto, apresentaremos os dados relativos à população estudantil em Cabo Verde, em termos das áreas que estudam e da sua origem geográfica. De forma a discutir a equidade do acesso, fundamental para avaliar o potencial transformador das Instituições de Ensino Superior na sociedade cabo-verdiana e o seu papel na democratização do país (BLESSINGER; ANCHAM, 2015; CASTELLS, 2009; CLOETE; MAASEN; BAILEY, 2015), apresentaremos, ainda, dados relativos à origem social dos estudantes, assim como a sua distribuição por gênero.

Quase dois terços destes alunos estudam cursos relacionados com Ciências Humanas ou Ciências Exatas. Em menor número surgem as áreas das Ciências da Vida, Saúde e Ambiente (CABO VERDE, 2017), como se pode verificar na Tabela 5. 
Tabela 5. Percentagem de estudantes por Áreas Científicas (CABO VERDE, 2017)

Áreas

Ciências Sociais, Humanas, Letras e Línguas

Ciências da Vida, Ambiente e Saúde

Ciências Económicas, Jurídicas e Políticas

Ciências Exatas, Engenharia e Tecnologias
Percentagem

33

\section{ORIGEM GEOGRÁFICA}

Em Cabo Verde, as Instituições de Ensino Superior não estão distribuídas por todo o

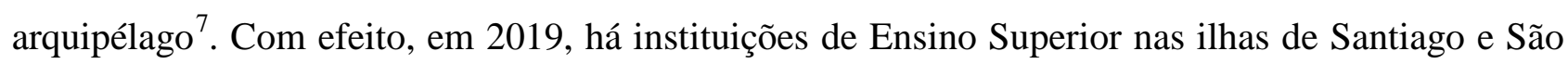
Vicente apenas. Ademais, a maioria absoluta das mesmas concentra-se nas maiores cidades destas ilhas - Praia e Mindelo. A exceção é, na ilha de Santiago, nas cidades de Assomada (onde está sediada a Universidade de Santiago e há um polo da Universidade de Cabo Verde) e Tarrafal (onde a Universidade de Santiago tem um polo).

Contudo, o número de estudantes de cada ilha é proporcional ao número de habitantes das mesmas, o que indicia um equilíbrio regional interessante num país em que estes indicadores revelam, frequentemente, situações menos favoráveis (INE, 2015). Por outras palavras, os dados, como exposto na tabela6, revelam que existe uma interessante mobilidade de estudantes, que se deslocam das suas ilhas para os maiores centros de forma a prosseguirem os seus estudos superiores.

\footnotetext{
${ }^{7}$ Cabo Verde é um país composto por 10 ilhas, 9 das quais habitadas. A maioria da população está concentrada nas ilhas de Santiago, onde se encontra a capital, Praia, e São Vicente, que são, também, os maiores polos culturais do país.
} 
Tabela 6. Origem geográfica dos estudantes do Ensino Superior (CABO VERDE, 2017)

\begin{tabular}{c|cc}
\hline \multicolumn{1}{l}{} & Ilha & Percentagem \\
\cline { 2 - 3 } & Santiago & 59 \\
\hline \multirow{2}{*}{} & São Vicente & 16 \\
& Sonto Antão & 12 \\
& Outras & 6 \\
\hline
\end{tabular}

\section{ORIGEM SOCIAL}

Embora não haja, oficialmente divulgados, números concretos sobre a origem social dos alunos do Ensino Superior, o fato de quase 50\% dos alunos terem algum tipo de apoio financeiro (BANCO MUNDIAL, 2012) para poderem prosseguir os seus estudos deixa antever alguma equidade social no acesso ao mesmo. A distribuição proporcional entre a origem geográfica dos alunos também aponta neste sentido.

Para estudar no Ensino Superior, em Cabo Verde, os alunos pagam uma quantia mensal, denominada de "propina”, cujo valor oscila entre os 70 e os 180 euros $^{8}$, com tendência a baixar, ao longo dos últimos anos ${ }^{9}$. Neste ponto, como realçam Brito (2017) e Langa (2013), a atribuição de bolsas e subsídios tem sido fundamental. Tem havido, ao longo do século XXI, uma inversão nas políticas públicas, no que diz respeito a bolsas de estudo, que, anteriormente eram, sobretudo para estudantes no estrangeiro. Em 2002, o governo deu 1658 bolsas para estudantes nacionais no estrangeiro e 633 para estudantes em território nacional. Dez anos depois, em 2012, os números já se haviam invertido: 628 bolsas para o estrangeiro e 2592 para estudantes em Cabo Verde (BRITO, 2017). Ademais, outras instituições, públicas e privadas, oferecem apoios e subsídios para estudantes, embora essas práticas tenham sido menos eficazes, nomeadamente empréstimos bancários, e, em alguns casos, de forma controversa ${ }^{10}$.

\footnotetext{
${ }^{8}$ Em termos de comparação, o salário mínimo nacional está fixado em cerca de 130 euros.

${ }^{9}$ Informações recolhidas junto das várias Instituições de Ensino Superior.

${ }^{10}$ Nomeadamente o apoio das Câmaras Municipais, como salienta Brito (2017, p. 143): “a utilização de recursos para financiar o ensino superior acaba por constituir-se num procedimento ilegal, razão pela qual o Tribunal de Contas tem agido para desincentivar essa prática.”
} 


\section{GÊNERO}

Por fim, um dos aspetos mais significativos do Ensino Superior em Cabo Verde tem a ver com a distribuição dos alunos por gênero. Com efeito, cerca de 60\% dos estudantes no país são mulheres. Elas, ao mesmo tempo, correspondem, em proporção superior, ao número de licenciados nas Instituições de Ensino Superior nacionais, o que indica que não só são em número superior, como o seu sucesso acadêmico é mais elevado. Significativamente, o número de mulheres estudantes representa uma Taxa de Escolarização Bruta de 29\%, contra 19\% dos homens. Elas também são a maioria em quase todas as áreas científicas, excetuando as Ciências da Vida, Ambiente e Saúde, conforme a Tabela 7:

Tabela 7. Percentagem de mulheres por Áreas Científicas (CABO VERDE, 2017)

\begin{tabular}{cc}
\hline Áreas & \% de mulheres \\
\hline Ciências Sociais, Humanas, Letras e Línguas & 67 \\
Ciências da Vida, Ambiente e Saúde & 32 \\
Ciências Económicas, Jurídicas e Políticas & 77 \\
Ciências Exatas, Engenharia e Tecnologias & 61 \\
\hline
\end{tabular}

Num país cujos indicadores de gênero e de igualdade social estão ainda aquém do desejado, estes valores podem indicar uma mudança de paradigma e de mentalidades a curto/médio prazo, através do empoderamento feminino. A política de ação social, apesar das dificuldades de sustentabilidade deste sistema (BRITO, 2017; SCHWARTZMAN, 2011), parece indicar uma maior democratização e equidade no acesso ao Ensino Superior e, naturalmente, a um capital simbólico (BOURDIEU, 2013) inestimável na emancipação dos jovens.

\section{QUALIDADE DO ENSINO SUPERIOR EM CABO VERDE}

Nesta seção nos propomos a tentar definir, sucintamente, o conceito de Qualidade no Ensino Superior, antes de apresentar alguns dos dados disponíveis que permitam avaliar a qualidade deste subsistema de ensino em Cabo Verde.

Mhlanga (2008) apresenta “Qualidade” como um conceito desdobrável nas seguintes categorias: excelência e perfeição; cumprimento dos seus propósitos; retorno do investimento nele feito; e poder transformacional. Olhando para a ideia de perfeição, Rostan e Vaira (2011, p. 57) remetem-nos para seguinte definição: 
[...] public policies which, using evaluation and selection tools and criteria, aim at formally promoting or recognising a level of quality in research and/or teaching higher than average. On the basis of this level, policies for excellence formally recognise and give institutions, their sub-units, or networks of institutions or sub-units, an apical status and position within the higher education system, and more financial resources.

Neste contexto, a qualidade é associada à excelência, que, por sua vez, deriva de políticas de avaliação e seleção, cujo resultado será a obtenção de recursos financeiros. A qualidade transformase em ago distintivo, atingido apenas por poucos. O Estado passa a avaliar as instituições com base na sua produtividade, eficiência e accountability, numa lógica de educação como serviço. Contudo, a produção de ciência e de conhecimento não são facilmente mensuráveis e as normas empresariais que esta visão pressupõe não são facilmente aplicáveis (LIMA, 2014; MHLANGA, 2008).

Como se constata, é um exercício difícil e em constante revisão, a medição da qualidade do Ensino Superior. Para os objetivos deste artigo, pretendemos, apenas, apresentar alguns indicadores bem concretos mais importantes, como a qualificação do corpo docente, as infraestruturas disponíveis e a pesquisa, tomando como medida, sempre que disponíveis, as próprias exigências legais do governo cabo-verdiano.

\section{QUALIFICAÇÃO DO CORPO DOCENTE}

Olhando para os dados do Anuário Estatístico do Ensino Superior, constatamos que há 1308 docentes a colaborar com as Instituições de Ensino Superior de Cabo Verde, divididos, conforme o grau académico, conforme a Tabela 8: 
Tabela 8. Docentes de acordo com o Grau Académico (CABO VERDE, 2017)

\section{Grau Académico}

Pós-Doutorado

Doutorado

Mestrado

Pós-Graduado

Licenciado
Total

3

186

625

83

411

\section{Rácio Aluno/Prof.}

68/1 (Padrão: 120/1)
20/1 (Padrão: 100/1)

$30 / 1$

Nesta visão geral, é visível que, na sua maioria, os docentes são Mestres ou Doutorados. Em ambos os quesitos, inclusivamente bem dentro dos requisitos previstos na lei: um doutor para cada 68 alunos e 1 Mestre para cada 20 alunos, quando o padrão é de 120 e 100, respetivamente. Contudo, esta não é a realidade de todas as Instituições. Com efeito, em 2015/2016, três instituições ficavam aquém dos valores exigidos (CABO VERDE, 2017). Outro aspeto de salientar é a elevada percentagem de professores apenas a tempo-parcial, que, em algumas instituições ultrapassa os 70\% do pessoal docente (BANCO MUNDIAL, 2012). Faltam, também, sistemas integrados e institucionalizados de recrutamento e avaliação do pessoal docente, como forma de controlo da qualidade do ensino (Idem).

\section{INFRAESTRUTURAS}

No que diz respeito às infraestruturas, a grande maioria das Instituições de Ensino Superior em Cabo Verde têm as suas próprias instalações, com o rácio de 56 alunos por sala. A maioria das instituições também usa as suas próprias instalações (CABO VERDE, 2017). Sendo um dos requisitos obrigatórios para a abertura de um ciclo de estudos a disponibilização de Laboratórios, sejam de Informática ou para outras áreas técnicas, acredita-se que os mesmos também estejam à altura das necessidades mínimas. O mesmo aplica-se à existência de Bibliotecas, embora a inexistência de um mercado editorial forte no país e os custos elevados associados à importação de livros sejam obstáculos fortes neste indicador (BANCO MUNDIAL, 2012). Ainda assim, falta divulgar dados mais objetivos e concretos neste quesito para uma avaliação mais acutilante desta realidade. 


\section{PESQUISA}

Por fim, aquele que tem sido um dos aspetos em que as IES de Cabo Verde têm ficado mais aquém: a Pesquisa. Cloete, Maasen e Bailey (2015), olhando para o continente africano, consideram que na génese do fraco desempenho das universidades africanas na pesquisa está a visão das mesmas como ferramentas de desenvolvimento. A escolha seria entre ter universidades instrumentalistas ou produtoras de conhecimento e inovação. Durante a colonização, a maioria destas instituições era, sobretudo, uma forma de formar profissionais nas áreas que a metrópole não podia ou queria recobrir. Após a descolonização, estas instituições ficaram sob a tutela de governos, frequentemente fracassados. Nestes contextos, durante décadas, imperou a lógica instrumentalista: universidades como impulsionadoras do desenvolvimento onde os governos falham. Ao invés, uma aposta em instituições dinâmicas que possam responder, de forma autónoma, às demandas socioeconómicas das suas populações, teria resultado em universidades em que a pesquisa e a inovação científica estariam já consolidadas (CLOETE; MAASEN; BAILEY, 2015).

Em Cabo Verde, o surgimento mais tardio de um sistema de Ensino Superior e a relativa estabilidade da democracia do país, poderia indicar uma aposta diferente nas políticas de pesquisa e inovação. Contudo, desde o início, o modelo de financiamento incremental posto em prática em Cabo Verde (BRITO, 2017) e a falta de políticas definidas para a divulgação da pesquisa (BANCO MUNDIAL, 2012; SCHWARTZMAN, 2011) fizeram prevalecer a lógica instrumentalista ou de serviços (CLOETE; MAASEN; BAILEY, 2015) que impera no restante do continente africano.

Olhando para os indicadores selecionados, saltam à vista algumas conquistas, embora não desacompanhadas de desafios exigentes. Destaca-se, ainda, a existência de poucos dados oficiais concretos. Torna-se, neste sentido, cada vez mais premente a coleta e divulgação de dados concretos sobre as políticas de qualidade das IES de Cabo Verde. Na sequência, o Estado poderia, com maior legitimidade e acutilância levar a cabo medidas de garantia e manutenção da qualidade (SCHWARTZMAN, 2011; VARELA; PACHECO, 2014).

Uma medida de relevo seria uma avaliação externa de todas as instituições de Ensino Superior. Como afirmam Varela e Pacheco (2014, p. 34), em “Cabo Verde, que não dispõe de um referencial obrigatório, a avaliação externa é uma realidade discursiva significativa, carecendo, ainda, de práticas consolidadas e institucionalmente interiorizadas”.

Em 2014/2015, fez-se tal avaliação. Todas as Instituições de Ensino Superior participaram, elaborando um relatório de autoavaliação, que serviu de base à subsequente avaliação externa. Infelizmente, nem os dados recolhidos nem as classificações, da qual se faria o primeiro ranking das 
Universidades de Cabo Verde, um dos caminhos possíveis para se atingir a excelência (ROSTAN; VAIRA, 2011).

\section{RELEVÂNCIA DO ENSINO SUPERIOR EM CABO VERDE}

Discutir a relevância do Ensino Superior significa debater a sua efetiva mais-valia; o que se ganha com a sua existência. Mas, para tal, urge clarificar que tipo de mais-valia se procura. Vários autores (BANCO MUNDIAL, 2012) defendem como fator de relevância do Ensino Superior a sua adequação às finalidades. Mas qual é, de fato, a sua finalidade? Do ponto de vista do estudante, será terminar o seu curso e ter as ferramentas necessárias para a sua inclusão social e profissional. Para outros (Idem), poderá ser muito mais vasto que esta noção individual e ter repercussões no todo da sociedade. Outros defendem a sua boa qualidade, conceito já abordado, mas que, na nossa visão, não deve constituir-se apenas como um fim em si mesmo, mas sim o veículo para o seu contínuo desenvolvimento.

Opiniões mais recentes (CLOETE; MAASEN; BAILEY, 2015; MHLANGA, 2008) defendem a relevância como a forma como o Ensino Superior serve a sociedade em que se insere.Naspalavras de Mhlanga (2008, p. 131),

[U]niversities in the developing world are socially embedded institutions; they serve, first and foremost, the interests and needs of societies in which they are located. They recruit students from those societies and they reform their curricula in ways responsive to society's needs. In many contexts they are viewed as a key social agency for engendering social and economic development, including the generation of knowledge. Thus, there are certain expectations society has of a university and these must be sufficiently met if the institution is to remain relevant.

Desta forma, a relevância das Instituições de Ensino Superior e de todo o subsistema deriva da sua inserção social e da sua capacidade de se assumirem como agentes de desenvolvimento.Tomando esta última definição como medida, teremos em atenção fatores económicos, sociais e culturais para a nossa análise.

\section{RELEVÂNCIA ECONÓMICA}

Indo muito além do escopo deste artigo fazer uma análise aprofundada da situação económica de Cabo Verde, neste ponto procuraremos, de forma simples, a) olhar para as principais apostas do atual governo do país para impulsionar a economia nacional e b) apresentar, sucintamente, as medidas previstas de apoio à empregabilidade, ambos a partir do Programa da IX 
Legislatura, para o período de 2016-2021 (Cabo Verde, 2016). Na sequência, confrontaremos estes eixos com a apresentação do tipo de diplomados das Instituições de Ensino Superior de Cabo Verde e com a empregabilidade dos mesmos.

Assim, de acordo com o Programa do Governo da IX Legislatura de Cabo Verde, podemos destacar como eixos de desenvolvimento económico-prioritários o Turismo, a Economia Azul, envolvendo tudo o que se relacione com o mar e a aposta nas TIC, perspetivando Cabo Verde como um centro tecnológico inovador. Estes setores nascem da realidade de uma economia em que os setores secundário e terciário são ainda muito débeis e numa ideia de desenvolvimento geopoliticamente fundamentada (CABO VERDE, 2016).

No que tange às medidas de incentivo ao emprego, destacaríamos, pela sua relevância para o Ensino Superior, políticas de incentivo aos estágios profissionais e o "reforço das competências dos licenciados nomeadamente, através de programas de reconversão de perfil e da qualificação” (CABO VERDE, 2016, p. 15). As primeiras escolhas são sintomáticas de uma aposta em áreas cuja profissionalização exige uma formação em áreas técnicas. As segundas apresentam traços claros do que Lima (2014) chama de vocacionalismo, um ensino voltado para a "aquisição de competências para competir, de qualificações funcionalmente adaptadas aos imperativos da 'economia do conhecimento’ e da ‘sociedade da aprendizagem’” (Idem, p. 14).

De acordo com os dados mais recentes, relativos a 2015/2016 (CABO VERDE, 2017), diplomaram-se, em diversos graus, nas IES de Cabo Verde 1365 alunos, nas seguintes áreas e graus, de acordo com a Tabela 9:

Tabela 9. Diplomados por Áreas Científicas (CABO VERDE, 2017)

\begin{tabular}{|c|c|c|c|c|}
\hline Áreas & Mestrado & Licenciatura & CESP & $\%$ \\
\hline $\begin{array}{c}\text { Ciências Sociais, Humanas, Letras e } \\
\text { Línguas }\end{array}$ & & 521 & 17 & 39 \\
\hline Ciências da Vida, Ambiente e Saúde & & 168 & 37 & 15 \\
\hline Ciências Económicas, Jurídicas e Políticas & 18 & 404 & 5 & 31 \\
\hline $\begin{array}{c}\text { Ciências Exatas, Engenharia e } \\
\text { Tecnologias }\end{array}$ & & 175 & 17 & 14 \\
\hline TOTAL & 18 & 1268 & 76 & \\
\hline
\end{tabular}


Cerca de 40\% dos licenciados em Cabo Verde formam-se nas áreas das Ciências Humanas, Jurídicas e Sociais. Áreas, portanto, não indicadas como os principais motores do desenvolvimento económico do país. Como nota Schwartzman (2011), o mercado de trabalho, em Cabo Verde, é caraterizado pela informalidade e baixa qualificação da mão-de-obra. Contudo, este aumento de profissionais altamente qualificados, mas em áreas de empregabilidade mais difícil e menor produtividade económica podem levar a acentuadas tensões e ao descrédito do Ensino Superior (CLOETE; MAASEN; BAILEY, 2015; MHLANGA, 2008).

Ademais, o desemprego entre os licenciados ronda os 12\%, embora esta percentagem esteja a diminuir ao longo da última década, de acordo com os dados mais recentes. Esta percentagem torna-o no subsistema de ensino com a maior taxa de desemprego no país (INE, 2018). Como salienta Lima, esta incapacidade do Ensino Superior se mostrar relevante neste quesito, leva-o a ser confrontado "empiricamente por fenómenos crescentes de desemprego estrutural, de trabalho intermitente e de trabalho precário, de trabalho sem direitos, afetando profundamente a geração jovem mais escolarizada que alguma vez existiu em muitos países” (LIMA, 2014, p. 14).

\section{RELEVÂNCIA SOCIAL E CULTURAL}

Adentro da concepção de relevância do Ensino Superior privilegiada neste capítulo, não bastaria analisar aspetos económicos e de empregabilidade. As necessidades reais e imediatas das comunidades em que se inserem só podem ser atendidas olhando para fatores, muitas vezes, não tão facilmente mensuráveis (CLOETE; MAASEN; BAILEY, 2015; LIMA, 2014). Assim, nesta seção, tomaremos como medida, fundamentalmente, a) aspetos relevantes da realidade social e cultural do país e b) os dados sobre a população estudantil de Cabo Verde, anteriormente apresentados, assim como as políticas explícitas das IES de Cabo Verde.

A relativa equidade no acesso ao Ensino Superior, já anteriormente abordada, deixa perceber, adentro deste sistema de ensino, configurações sociais distintas das que se observam na sociedade deste país. Tomemos a questão de gênero como primeiro exemplo. Já referimos a predominância feminina entre os estudantes e os licenciados de Cabo Verde, com 61\% e 64\% do total das duas populações, respectivamente (CABO VERDE, 2017).

Por outro lado, a maioria dos indicadores revela, ainda, uma sociedade com uma profunda desigualdade de gênero. Mais de metade dos pobres no país (53\%) são mulheres, muitas delas responsáveis pelos seus agregados familiares. Ao mesmo tempo, em 2016, 17,6 \% das mulheres estavam desempregadas, contra 12,9\% nos homens (INE, 2017). Na Tabela 10, podemos observar 
os números relativos a influência e poder, também indicadores do desequilíbrio de gênero. Quer no setor político, como no empresarial, as desigualdades de gênero são notórias. Poderá uma nova geração de mulheres, altamente qualificadas, influenciar as estruturas de poder e desigualdade existentes na sociedade, como sugerem Dahms e Lybeck (2014)?

Tabela 10. Indicadores de Gênero: Influência e Poder (INE, 2017)

\begin{tabular}{ccc}
\hline Indicador & Mulheres & Homens \\
\hline Ministros & 3 & 11 \\
Deputados Nacionais & 17 & 55 \\
Presidentes de Câmara & 0 & 22 \\
Liderança nas Empresas & $35 \%$ & $65 \%$ \\
\hline
\end{tabular}

No mesmo sentido, as políticas que têm proporcionado uma maior igualdade de acesso ao Ensino Superior a estudantes de diversas origens geográficos e sociais poderão impulsionar mudanças estruturais no sentido de uma maior democratização, igualdade de oportunidades e desenvolvimento para os mais variados setores da sociedade (CLOETE; MAASEN; BAILEY, 2015). Com efeito, a população do país ainda contempla 35,2\% de pobres ou muito pobres (INE, 2015a) e a maioria reside nos meios rurais (Idem), afastada dos grandes centros educativos, portanto. A taxa de abandono escolar é muito elevada, assim como o insucesso escolar, ferindo a eficácia social de todo o sistema educativo de Cabo Verde, que, assim, perpetua e cristaliza assimetrias sociais já de si profundas em Cabo Verde (MOURA, 2014).

Em consequência desta desigualdade e dificuldade de ascensão social, a Emigração tem sido uma das formas de emancipação dos indivíduos (FERNANDES, 2006; LANGA, 2013). O mesmo acontecia por razões óbvias de inexistência de opções em Cabo Verde, até ao século XXI. Contudo, já em 2002, havia mais estudantes no país que no estrangeiro (SCHWARTZMAN, 2011). Esta inversão deixa adivinhar que, seguramente, a expansão do Ensino Superior no país veio aumentar exponencialmente as possibilidades de ter acesso a uma maior formação de forma mais igualitária e democrática. Ainda assim, o motivo mais alegado para emigrar, continua a ser, em 2015, para estudar, sobretudo entre os jovens entre os 18 e os 24 anos (INE, 2015b). O kaminhu lonji ${ }^{11}$, apesar

\footnotetext{
${ }^{11}$ Expressão em Língua Cabo-verdiana, que se pode traduzir por “caminho longo”, usada na famosa canção “Sodade”, interpretada por Cesária Évora, e que se refere à emigração e ao longo caminho percorrido por estes emigrantes.
} 
das maiores oportunidades que o atual sistema de Ensino Superior oferece, continua a estar bem aberto e enraizado na mente dos jovens cabo-verdianos (LANGA, 2013).

Por fim, Cabo Verde, como país jovem, ex-colónia, apresenta, ainda, profundas assimetrias culturais, que marcam decisivamente as estruturas sociais e de desenvolvimento da nação (FERNANDES, 2006; MONIZ, 2009). Desde logo, o processo de colonização no país, pela inexistência de população nas ilhas, levou à criação de uma nova sociedade, na interação desigual entre colonizador europeu e o escravo africano (MONIZ, 2019). Neste contexto, a superioridade cultural, advinda da superioridade política e social, da parte europeia prevaleceu, ante à falta de uma cultura de substrato prévia e a sua militância, deixando, no povo cabo-verdiano, um conflito identitário nas elites nacionais, nunca expressamente resolvido (BRITO-SEMEDO, 2006; FERNANDES, 2006). Este conflito, defende Moniz (2009), foi sempre particularmente visível no sistema educativo nacional e fratura toda a sociedade, na proximidade que certos grupos e manifestações expressam em relação a cada uma das partes da herança do país (FERNANDES, 2006).

Uma das manifestações visíveis desta assimetria reside na situação linguística do país. Por um lado, a língua oficial e de prestígio é a Língua Portuguesa. É usada nas situações mais formais, na escrita de documentos oficiais e nas escolas, desde o primeiro ano de escolaridade (VEIGA, 2002). Naturalmente, esta é herança do antigo colonizador. Por outro lado, a língua materna e do quotidiano da maioria absoluta da população é a Língua Cabo-verdiana, de base portuguesa, mas com influências das línguas africanas. No entanto, esta domina apenas nos contextos menos formais e o seu ensino sistematizado está arredado das escolas (Idem). Esta diglossia (DUARTE, 2003) é estruturante nos desequilíbrios sociais do país: o domínio da língua oficial facilita o sucesso escolar e, consequentemente, muitas vezes, profissional e social (RODRIGUES, 2014). Contudo, conseguir esse domínio, pelas debilidades do seu ensino (SANCHES, 2008), é privilégio das classes já mais favorecidas, servindo como fator de cisão social e de desenvolvimento (MONIZ, 2009; RODRIGUES, 2014).

O desenvolvimento e consolidação de um sistema de ensino superior podem levar a uma reestruturação destas assimetrias económicas, sociais e culturais (DAHMS; LYBECK, 2014). No caso de Cabo Verde, poucas décadas depois do nascimento deste subsistema de ensino, é fundamental relembrar que poucas gerações tiveram esta oportunidade de investir na sua educação e no seu crescimento pessoal e profissional. Esta poderá ser uma das maiores conquistas do Ensino Superior em Cabo Verde e um dos seus mais inequívocos sinais para a efetiva democratização do país. 


\section{CONCLUSÕES}

Feita esta apresentação de algumas das suas principais características e, a despeito de muitos desafios que ainda tem pela frente, podemos concluir que o sistema de Ensino Superior, em Cabo Verde, tem dado passos consistentes.

Há uma diversidade de áreas de formação e de graus acadêmicos assinalável e uma crescente política de regularização deste setor. A população estudantil revela que alguns grupos sociais menos favorecidos têm tido apoios no acesso e manutenção no Ensino Superior, na expectativa de que o capital simbólico adquirido reconfigure as estruturas sociais existentes, conferindo maior equidade à sociedade. Ainda assim, há ainda muito que pode ainda ser feito em termos de políticas globais de aferição, manutenção e incentivo à qualidade do sistema em si e de cada instituição. Tais políticas poderão levar a uma maior relevância, ou seja, importância para a sociedade, do Ensino Superior em Cabo Verde.

Tendo em conta os papéis do Ensino Superior, defendidos por Castells (2009) e anteriormente apresentados, é importante reter que a) os mesmos foram sendo historicamente consolidados em sistemas com séculos de existência; e que b) se o Ensino Superior assumir, de fato, a sua natureza, estas funções são desempenhadas naturalmente. Assim, concluiremos este estudo analisando, com base nos dados apresentados, como, em tão poucos anos, o sistema de Ensino Superior tem cumprido estes papéis, apontando sugestões, sempre que possível.

Pelo histórico deste sistema, podemos concluir que tem havido um rápido crescimento e estabilidade no Ensino Superior em Cabo Verde. Este fenômeno será fruto da vontade política para tal, assim como de projetos institucionais que têm encontrado o seu espaço e produzido valores que vão ao encontro do anseio da comunidade. Acreditamos que, historicamente, as IES e as políticas públicas têm uma oportunidade histórica na legitimação da cultura e histórias locais, tantas vezes ostracizadas (FERNANDES, 2006; MONIZ, 2009). Além das competências técnico-científicas, os estudantes do Ensino Superior em Cabo Verde devem assumir valores humanistas e sociais, que lhes permitam, depois da conclusão dos seus estudos, ser cidadãos que contribuam para uma democratização da sociedade.

Isto porque os discentes do presente serão as elites dominantes do futuro. Os sinais de equidade no acesso ao Ensino Superior em Cabo Verde são um dos sinais mais promissores do potencial transformador deste sistema. Idealmente, a democratização do acesso à formação superior levará à emancipação destes indivíduos (BLESSINGER; ANCHAN, 2015) e dos grupos sociais em que estão inseridos. Ainda assim, será importante conhecer melhor as hierarquias existentes dentro 
desta democratização: terá o mesmo peso simbólico estudar no estrangeiro como em Cabo Verde? Haverá instituições e/ou cursos cujo acesso ainda esteja circunscrito a algumas classes sociais privilegiadas?

A resposta a estas questões é fundamental, pois, apenas através dela poderemos depreender se o Ensino Superior tem cumprido o seu papel de formador, socialmente responsável, da força laboral. Como vimos, há ainda muita desigualdade social (INE, 2015), que se repercute na educação e no acesso ao emprego (MOURA, 2014). Ao mesmo tempo, paira sobre este subsistema a ameaça da acomodação às necessidades do mercado de trabalho (LIMA, 2014). Tendo em vista a cabal assunção deste papel de formador da força laboral do país, as IES devem assumir o papel de produtores de conhecimento e inovação (CLOETE; MAASEN; BAILEY, 2015), que as levarão a estar menos dependentes das ações governamentais e a poderem, não só responder às demandas da sociedade, como serem líderes no desenvolvimento da mesma.

São estes mesmos valores que, a médio prazo, poderiam transformar as Instituições de Ensino Superior em Cabo Verde em produtores de conhecimento científico sistemático e socialmente útil. Esta metamorfose de instituições instrumentalistas para transformadoras do panorama de inovação, pesquisa e desenvolvimento (CLOETE; MAASEN; BAILEY, 2015) de Cabo Verde, por parte das Instituições de Ensino Superior é, porventura, o passo que mais poderá concretizar o seu potencial transformador da sociedade de Cabo Verde. 


\section{REFERÊNCIAS}

BANCO MUNDIAL. Construindo o Futuro: Como é que o Ensino Superior Pode Contribuir Para a Agenda de Transformação Económica e Social de Cabo Verde. 2012. 165 p.

BLESSINGER, P.; ANCHAN, J. P. Democratizing Higher Education. New York: Routledge, 2015. 250 p.

BOURDIEU, P. Capital simbólico e classes sociais. Novos estudos - CEBRAP [on-line], 2013, n. 96, p. $105-115$.

BRITO, A. A Governança Universitária: Modelos e Práticas. O Caso da Universidade de Cabo Verde. Tese (Doutorado), Universidade de Lisboa, 2017. 382 p.

BRITO-SEMEDO, M. A construção da identidade nacional - análise da imprensa entre 1877 e 1975. Praia: Instituto da Biblioteca Nacional e do Livro, 2006. 452 p.

CABO VERDE. Anuário Estatístico do Ensino Superior. Praia: Ministério da Educação, 2017. 88 p.

Programa do Governo da IX Legislatura. 2016. Disponível em: <http://www.governo.cv/index.php/ programa-do-governo>. Acesso em: 18 dez. 2018.

CASTELLS, M. Lecture on Higher Education. Palestra proferida na Universityofthe Western Cape, em 7 de Agosto de 2009. Disponível em: <www.uchile.cl/documentos/lecture-on-higher-education_113390_49_1026.pdf>. Acesso em: 21 jan. 2018. 6 p.

CLOETE, N.; MAASEN, P.; BAILEY, T. Knowledge Production and Contradictory Functions in African Higher Education. Somerset West: African Minds, 2015. 312 p.

DAHMS, H. F.; LYBECK, E. R. Barriers and Conduits to Social Justice - Universities in the Twenty-First Century. In: SHEFNER, J. et al. Social Justice and the University. Globalization, Human Rights, and the Future of Democracy. Basingstoke: Palgrave Mcmillan, 2014. 356 p.

DUARTE, D. A. Bilinguismo ou diglossia? Mindelo: Spleen Edições, 2003. 152 p.

FERNANDES, G. Em busca da nação: notas para uma reinterpretação do Cabo Verde crioulo. Florianópolis: Editora da UFSC, 2006. 312 p.

INE. Estatísticas do Mercado de Trabalho 2017. 2018. Disponível em: <http://ine.cv/publicacoes/estatisticas-domercado-trabalho-2017/>. Acesso em: 18 dez. 2018.

III Inquérito às Despesas e Receitas Familiares. 2015. Disponível em: <http://ine.cv/publicacoes/resultadosdo-iii-inquerito-as-despesas-receitas-familiares-2015/>. Acesso em: 18 dez. 2018.

Inquérito Multi-objectivo Contínuo 2014. Estatísticas das Migrações. 2015. Disponível em:

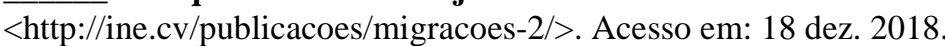

Mulheres e Homens em Cabo Verde. Factos e Números. 2017. Disponível em: <http://ine.cv/publicacoes/mulheres-homens-cabo-verde-factos-numeros-2017/>. Acesso em: 18 dez. 2018.

LANGA, P.V. Higher Education in Portuguese Speaking African Countries - a Five Country Baseline Study. Somerset West: AfricanMinds, 2013. 105 p.

LIMA, L.; Políticas e governação da educação superior. In: FERREIRA, A. C. P.; Nas pagadas das Reformas Educativas. Praia: EdiçõesUni-CV, 2014. 85 p.

MHLANGA, E. Quality Assurance in Higher Education in Southern Africa: The Case of the Universities of the Witwatersrand, Zimbabwe and Botswana. Tese (Doutorado), Universidade de Witwatersrand, 2008. 351 p.

MONIZ, E. A. Africanidades versus europeísmos - pelejas culturais e educacionais em Cabo Verde. Praia: Instituto da Biblioteca Nacional e do Livro, 2009. 374 p.

MOURA, A. F. Eficácia social (qualidade e equidade) do sistema educativo em Cabo Verde. Revista Lantuna, Assomada, n. 1, p. 65-84, jan./jul. 2014.

RODRIGUES, L. Pobre não fala português - análise etnográfica da Política e Planificação Linguística em Cabo Verde. Dissertação (Mestrado), Universidade do Porto, 2014. 130 p.

ROSTAN, M.; VAIRA, M. Questioning Excellence in Higher Education. Rotterdam: Sense Publisher, 2011.193 p. 
SANCHES, C. E. Factores do (in)sucesso escolar na disciplina de LP no $\mathbf{2}^{\mathbf{0}}$ ciclo do ES em Cabo Verde - contributo para o seu estudo. Dissertação (Mestrado), Universidade de Aveiro, 2008. 283 p.

SCHWARTZMAN, S. The growth of higher education and its potential contribution to economic growth in Cape Verde. Disponível em: <http://www.dgesc.gov.cv/index.php/ensino-superior-de-cv/estudos-sobre-es-de-cv>. Acesso em: 15 jan. 2018.

TAVARES, M. C. M. Evolução do Ensino Superior em Cabo Verde (1985- 2005). Monografia (Licenciatura), Universidade de Cabo Verde, 2010. 73 p.

TOLENTINO, A. C. Universidade e transformação social nos pequenos estados em desenvolvimento: o caso de Cabo Verde. Tese (Doutorado), Universidade de Lisboa, 2006. 463 p.

VARELA, B.; PACHECO. J. A. Avaliação externa da qualidade da educação. Os casos de Cabo Verde e Portugal. In: FERREIRA, A. C. P. Nas pegadas das Reformas Educativas. Praia: Edições Uni-CV, 2014. 85 p.

VEIGA, M. A construção do bilinguismo. Mindelo: Instituto da Biblioteca Nacional e do Livro, 2004. 186 p. 


\section{RESUMO}

Este artigo tem como objetivo analisar o potencial transformador que o Ensino Superior poderá ter na sociedade cabo-verdiana. Embora tenha um historial ainda breve, este subsistema de ensino tem mostrado uma forte dinâmica ao longo das últimas décadas em Cabo Verde. Dadas a sua particular relação com a sociedade, urge conhecer como pode modificar algumas estruturas sociais deste país. Tomando os dados oficiais mais recentes como corpus de análise, se avaliam a acessibilidade e equidade do Ensino Superior em Cabo Verde, assim como a sua qualidade e relevância. À luz das funções das universidades propostas por Castells, se defende que as Universidades cabo-verdianas pugnem por valores humanistas, que influenciem as elites por si formadas a instaurarem padrões mais democráticos na sociedade e no mercado de trabalho. Para tal, o Ensino Superior deve mudar para um paradigma transformador do panorama da inovação, pesquisa e desenvolvimento.

Palavras-chave: Ensino Superior. Cabo Verde. Transformação Social.

\section{ABSTRACT}

This article aims to analyze the transformative potential that Higher Education can have in Cape Verdean society. Although it has a short history, this subsystem of teaching has shown a strong momentum over the last decades in Cape Verde. Given its particular relationship with society, it is urgent to know how it can modify some social structures of this country. Taking the most recent official data as a corpus of analysis, the accessibility and equity of Higher Education in Cape Verde, as well as their quality and relevance, are evaluated. In the light of the functions of the universities proposed by Castells, it is argued that the Cape Verdean Universities should strive for humanistic values that influence the elites they have established to establish more democratic standards in society and in the labor market. To this end, Higher Education must change to a transformative paradigm of innovation, research and development.

Keywords: Higher Education. Cape Verde. Social transformation.

\section{RESUMEN}

Este artículo tiene como objetivo analizar el potencial transformador que la Enseñanza Superior podrá tener en la sociedad caboverdiana. Aunque tiene un historial todavía breve, este subsistema de enseñanza ha mostrado una fuerte dinámica a lo largo de las últimas décadas en Cabo Verde. Dadas su particular relación con la sociedad, urge conocer cómo puede modificar algunas estructuras sociales de este país. Tomando los datos oficiales más recientes como corpus de análisis, se evalúan la accesibilidad y equidad de la Enseñanza Superior en Cabo Verde, así como su calidad y relevancia. A la luz de las funciones de las universidades propuestas por Castells, se defiende que las Universidades caboverdianas pugnen por valores humanistas, que influencien a las élites por sí formadas a instaurar patrones más democráticos en la sociedad y en el mercado de trabajo. Para ello, la Enseñanza Superior debe cambiar a un paradigma transformador del panorama de la innovación, investigación y desarrollo.

Palabras clave: Enseñanza Superior. Cabo Verde. Transformación Social. 